\title{
Historiografía sobre las significaciones imaginarias de infancia en la cultura de Occidente ${ }^{1}$
}

\author{
Historiography on the imaginary meanings of childhood in the western \\ culture
}

Historiografia das significações imaginárias da infância na cultura do Ocidente

\author{
Cecilia Rincón Verdugo ${ }^{2}$ \\ Universidad Distrital Francisco José de Caldas, Colombia
}

Recepción: 09/05/2018

Evaluación: 18/06/2018

Aceptación: 29/06/2018

Artículo de Reflexión

DOI: $10.19053 / 01227238.6245$

\section{RESUMEN}

Este artículo da cuenta de una apuesta investigativa desarrollada en la tesis doctoral "Imaginarios sobre infancia, políticas públicas y prácticas pedagógicas", presentada para optar por el título de doctora en Pedagogía-unam-2013, en la cual se muestra cómo, desde la teoría de los imaginarios sociales, es posible explicar la constitución de la sociedad y la emergencia de propuestas sociales y culturales que cuestionan y replantean las dinámicas sociales instituidas, así como las interacciones entre los sujetos y la cultura. Con el análisis y la interpretación realizados desde un enfoque de investigación histórica cualitativa - interpretativa, se pretende develar cómo los imaginarios son formas de legitimación del orden social, proceso que se da entre continuidades, rupturas, discontinuidades; en clave de tiempo histórico, cada cultura ha configurado ese magma de significaciones imaginarias sobre la infancia presentes en nuestra cultura occidental, se ha ido conformado la infancia en cada época, en cada sociedad, las condiciones de vida, el trato, las interacciones adulto-niño y la experiencia infantil en los diferentes momentos del desarrollo de Occidente. Metodológicamente la historiografía asumió la dinámica de construcción de los imaginarios sociales que se produce entre lo evidente y la opacidad, por lo que, para interpretarlos, develarlos y desentrañarlos, se tomaron - como fuente documental- libros, archivos y artículos que permitieron comprender cómo se ha ido indagado y conceptualizado la infancia, los niños y las niñas en diferentes momentos en la cultura de Occidente, con lo

$1 \quad$ Este artículo es parte de la tesis doctoral "Imaginarios sobre infancia, políticas públicas y prácticas pedagógicas", investigación realizada para optar por el título de doctora en Pedagogía de la Universidad Nacional Autónoma de México, finalizada en el año 2013. La investigación contó con el financiamiento de las becas CONACYT.

2 Doctora en Pedagogía de la Universidad Nacional Autónoma de México, decana de la Facultad de Ciencias y Educación de la Universidad Distrital Francisco José de Caldas, docente-investigadora de la maestría en Infancia y Cultura uDFJC, directora del grupo de investigación INFANCIAS-UDFJC, oRCID https://orcid.org/0000-0003-2516-0038. Correo electronico: rinconceci@yahoo.com 
cual se realiza una historiografía que permite develar la permanencia o las transformaciones que se han dado en la forma de significar la infancia.

Palabras clave: infancia; significaciones imaginarias; historiografía; instituido e instituyente.

\section{ABSTRACT}

This article presents the research doctoral work entitled "Imaginaries about childhood, public policies and pedagogical practices", - UNAM-2013. Here it is shown how, from the theory of social imaginaries, it is possible to explain the constitution of society and the emergence of social and cultural proposals that question and rethink the social dynamics instituted, as well as the interactions between subjects and culture.

The analysis and interpretation were carried out from a qualitative - interpretive historical approach, and we aimed to unveil the imaginaries as forms of legitimation of the social order and as a process that occurs between continuities, ruptures, discontinuities; in accordance with the historical time. In our western culture, every culture has configured that magma of imaginary meanings about childhood. Each period, each society, their living conditions, their treatment conventions, their adult-child interactions, and their childhood experience have shaped the notion of childhood in different moments of the development of the West.

Methodologically, historiography assumed the dynamics of social imaginaries' construction that occurs between "the evident" and "the opacity", so that, to interpret; unveil; and unravel them, books; files; and articles were taken as a documentary source that allowed us to understand how childhood and children have been studied and conceptualized at different in the western culture. This historiography reveals the permanence or transformations in the way people mean childhood.
Keywords: childhood; imaginary meanings; historiography; the Instituting and the Instituted.

\section{RESUMO}

Este artigo propõe uma aposta investigativa desenvolvida na tese de doutorado "Imaginário sobre infância, políticas públicas e práticas pedagógica", apresentada para fazer jus ao título de doutora em Pedagogia-UNAM-2013, na qual se mostra como, desde a teoria dos imaginários sociais, é possível explicar a constituição da sociedade e a emergência de propostas sociais e culturais que questionam e reorganizam as dinâmicas sociais instituídas, assim como as interações entre os sujeitos e a cultura. Com a análise e a interpretação realizadas a partir de uma perspectiva histórica qualitativa - interpretativa, se pretende mostrar como os imaginários são formas de legitimação da ordem social, processo que se dá entre continuidades, rupturas, descontinuidades; num recorte de tempo histórico, cada cultura configurou esse magma de significações imaginárias sobre a infância presentes em nossa cultura ocidental, conformando a infância de cada época, em cada sociedade, as condições de vida, o trato, as interações adulto-criança e a experiência infantil nos diferentes momentos do desenvolvimento do Ocidente. Metodologicamente a historiografia assumiu a dinâmica de construção dos imaginários sociais que se produzem entre o visível e a opacidade, de modo que, para interpretá-los, desvelá-los e desentranhá-los, se tomaram - como fonte documental - livros, arquivos e artigos que permitiram compreender como foi indagada e conceitualizada a infância, os meninos e as meninas em diferentes momentos da cultura do Ocidente, com o que se realiza uma historiografia que permite desvelar a permanência ou as transformações que foram dadas na forma de significar a infância.

Palavras-chave: infância; significações imaginárias; historiografia; instituído e instituinte. 


\section{INTRODUCCIÓN}

El presente artículo, tiene como objetivo dar cuenta de una historiografía de las significaciones imaginarias de infancia en la cultura de Occidente, a partir de la identificación de tres matrices histórico-culturales ${ }^{3}$ que han orientado la construcción de discursos y prácticas sobre la infancia: la infancia premoderna-antigua; la infancia moderna y la infancia contemporánea. Se parte de considerar que, desde estas matrices históricas, no lineales, se constituyen tres grupos de significaciones imaginarias que han determinado y orientado la construcción histórica y el devenir de la infancia, los discursos, las prácticas y las instituciones creadas para su cuidado y formación.

Dentro de la investigación "Imaginarios sobre infancia, políticas públicas y prácticas pedagógicas", para evidenciar los imaginarios sociales presentes en la política pública y la práctica pedagógica de un grupo de maestros en Colombia era necesario preguntarse por ¿cómo ha emergido la infancia como categoría histórico-social y cómo se ha significado a los niños y las niñas en la cultura de Occidente?, para así construir un referente historiográfico que permitiera, en el marco de la investigación, develar la presencia y la permanencia de esas significaciones en la manera como los maestros y la política orientan su práctica y sus programas para la infancia, pero, además, cómo se han incorporado esas significaciones que podemos llamar instituyentes en tanto han ido transformando las condiciones de vida y existencia de nuestros niños.

\section{Referentes teóricos y conceptuales}

Los imaginarios sociales se producen entre la opacidad y lo evidente, por tanto, interpretarlos, develarlos y desentrañarlos implicó ingresar en ese mundo de interacciones y relaciones humanas que definen al sujeto en la acción y, desde el lenguaje, hacer emerger ese sinnúmero de significados y sentidos no explícitos que, al volverse enunciados, evidenciaron una amalgama de simbolizaciones, afectos, sentimientos y representaciones sobre la niñez en un contexto histórico determinado. Así,

(...) reconstruir históricamente la infancia significa buscar, dentro de cada formación social, la configuración prevaleciente de significados, articulándolos al conjunto de representaciones que, en el imaginario social, se relacionan con los diferentes momentos de la existencia humana, en la trayectoria de vida, desde la concepción hasta la muerte. De este modo las representaciones sociales sobre la infancia tienen que ver con el conjunto de representaciones sobre los otros momentos

3 Esas matrices obedecen a tres grandes épocas del desarrollo de la humanidad, como son la premodernidad, la modernidad y la posmodernidad o contemporaneidad. Son definidas en cuanto a sus discursos y prácticas y las significaciones de infancia que se consolidan desde la invisibilidad a la visibilidad de los niños y las niñas en la sociedad de Occidente. 
de la existencia, con aquellas representaciones que reflejan el sentido de la vida, de la muerte, del paso del tiempo y de las relaciones con los otros"4.

La constitución histórica de grupos de significaciones sobre la infancia demanda mirar en las prácticas socioculturales el conjunto de imágenes, representaciones, concepciones, afectos, acciones y discursos que configuran un imaginario que orienta las formas de percibir la realidad y modelan el pensamiento, la acción, y determinan las experiencias vividas durante y con la infancia.

En este sentido, la construcción social se produce como historia, como acontecimiento, y en este enfoque la historia se distancia de las concepciones tradicionales (datos, fechas, cronologías), se inscribe esta visión en un campo de trabajo que recupera diferentes aspectos de la historia del hombre como la cultura, las significaciones, la vida cotidiana, las mentalidades colectivas y las vivencias religiosas, etcétera, se resignifican estos territorios con fuentes y visiones distintas; como lo conceptualizó Lucien Febvre, la historia se hace no solo con lo económico, lo político y lo social, sino también, con "todo lo que siendo del hombre depende del hombre, sirve al hombre, significa la presencia, la actividad, los gustos y las formas de ser del hombre" ${ }^{\prime}$.

En el contexto de esta historia interpretativa, lo imaginario se interesa por comprender cómo se entrelazan, se correlacionan, y confluyen lo material y lo ideológico; la manera como los hombres conciben las sociedades en cada momento histórico, las visiones del mundo que se forjaron, sus mentalidades y representaciones más allá de la sucesión de esquemas y eventos que obedecen a una racionalidad esquemática de causalidad o finalidad lógica y racional. "La historia no es secuencia determinada, es creación, emergencia de alteridad radical, incesante auto-transformación, creación de nuevas formas de ser que no obedecen a un esquema de determinidad"6.

La sociedad en su proceso de auto-creación constituye un elemento, lo histórico social. En palabras de Castoriadis ${ }^{7}$, lo histórico social es creación ontológica de nuevas formas, lo histórico social se encarna en las instituciones y las significaciones imaginarias sociales que llevan a la formulación de nuevas lógicas y realidades culturales.

Así, los imaginarios son significaciones sociales, construcciones de sentido que crean mundo; son creaciones efectivas en tanto producen efectos en todos los ámbitos de la vida, están en permanente cambio y transformación a partir de la actividad humana, son creación incesante. Son significaciones simbólicas que determinan la experiencia social y prefiguran comportamientos, actitudes, imágenes y sentimientos que movilizan las acciones. Esta dimensión simbólica nos lleva a pensar que lo "creíble", lo efectivo en un grupo social, lo que motiva

\footnotetext{
4 Lucía Rabello de Castro, Infancia y adolescencia en la cultura del consumo (Argentina: Lumen, 2001), 10.

5 Lucien Febvre, Combates por la historia (Barcelona: Editorial Ariel, 1982), 227.

6 Raúl E. Anzaldúa Arce, "Lo imaginario como significación y sentido", en Imaginario social: creación de sentido, coord. por Raúl E. Anzaldúa (México: Universidad Pedagógica Nacional, 2010), 27.

7 Cornelius Castoriadis, La institución imaginaria de la sociedad (Francia: Editorial Senil, 1975).
} 
y orienta las actuaciones, está estructurado por sistemas de percepción socialmente determinados.

Los imaginarios sociales son un conjunto de imágenes mentales producidas en una sociedad a partir de herencias, creencias y transferencias relativamente conscientes que operan en una época determinada y se transforman en una multiplicidad de tiempos. Este conjunto de representaciones, imágenes y significaciones se nutre de las diferentes formas de la vida social y se encarnan en las prácticas sociales.

Las significaciones imaginarias de infancia se han ido construyendo con los aportes teóricos procedentes de los estudios históricos, psicológicos, sociales y culturales, y hoy podemos decir que se ha logrado configurar un "campo de estudio" $^{\prime 8}$ interdisciplinario que permite ubicar la infancia como sujeto-objeto de investigación. En este campo de estudios, la infancia es abordada como una construcción histórica social, ligada a la cultura, y asumirla como objeto de estudio ha exigido transitar por fronteras y marcos epistémicos diversos, con lecturas interpretativas que develan las formas de constitución de los sujetos, de los saberes y de las prácticas.

Desde esta perspectiva se encuentra en el entramado de constitución de una sociedad un magma de significaciones consideradas como instituidas, en tanto en el proceso histórico social han sido internalizadas por los sujetos y son compartidas socialmente, pues él llega a un mundo ya objetivado en el cual "la vida cotidiana se presenta como una realidad interpretada por los hombres y para ellos tiene el significado de un mundo coherente" individuos deseables, ellos y ellas son producto del proceso de socialización en el cual se recrea cada una de las instituciones y las significaciones sociales de su sociedad. Así, el individuo es creación social, y un conjunto de individuos crea una sociedad. Es en esta relación permanente en la cual los sujetos ya socializados asumen las instituciones y las significaciones establecidas, consolidando un imaginario instituido y socialmente compartido.

De igual forma, estableciendo desplazamientos, rupturas y discontinuidades en las maneras de ser, sentir, pensar y decir sobre la infancia, se encuentra un grupo de significaciones consideradas como instituyentes, desde las cuales se configura el imaginario radical social instituyente que desde la perspectiva de Cornelius Castoriadis (1975) crea y representa cosas, objetos, figuras, formas, imágenes que en una relación dialéctica entre la psique y la sociedad generan

$8 \quad$ El concepto de campo de estudio se puede definir desde la noción foucaultiana de campo enunciativo: "La configuración del campo enunciativo comporta también formas de coexistencia. Estas dibujan ante todo un campo de presencia (y con ello hay que entender todos los enunciados formulados ya en otra parte y que se repiten en un discurso a título de verdad admitida, de descripción exacta, de razonamiento fundado o de premisa necesaria; hay que entender tanto los que son criticados, discutidos y juzgados, como aquellos que son rechazados o excluidos); en ese campo de presencia, las relaciones instauradas pueden ser del orden de la verificación experimental, de la validación lógica, de la repetición pura y simple, de la aceptación justificada de la tradición y la autoridad, del comentario, de la búsqueda de las significaciones ocultas, del análisis del error." (Foucault, 1976, 93) (cursivas del original). Entonces, por campo de estudio se puede entender las relaciones entre los diversos "discursos" de los distintos saberes científicos en torno a un objeto de estudio como la infancia.

9 Peter L. Berger y Thomas Luckmann, La construcción social de la realidad (Argentina: Amorrortu editores, 2003), 34 
transgresiones, discontinuidades y rupturas, propiciando un espacio de construcción colectiva humana.

Realizar una historiografía de las significaciones imaginarias sobre la infancia involucra esa relación entre lo colectivo y lo singular, la cual se teje desde lo que la gente dice, siente, piensa sobre la infancia, una construcción histórica y social que se demarca entre lo instituido y lo instituyente, así como entre lo hegemónico y lo alternativo en una búsqueda permanente de la legitimidad y reconocimiento en sociedades y culturas concretas.

\section{Precisiones metodológicas}

Entre otros elementos, lo que define la conformación de una historiografía sobre los imaginarios de infancia es la preocupación por un grupo poblacional particular, es mirar la constitución de esas significaciones sobre la infancia, en relación con la configuración identitaria de ese grupo social en un tiempo y espacio determinados. Unas significaciones imaginarias que se instituyen desde y en las instituciones sociales, como son el lenguaje y la práctica, y que permiten develar la relación entre el sujeto (psiquis) y la sociedad (colectivo). Esta historiografía asume, como elemento central de su estructura, el despliegue de lo histórico social para develar cómo estas significaciones imaginarias sociales se anclan en la tradición cultural y en una relación dialéctica se reconfiguran y se imbrican, modificando lo institucionalizado e instituyendo nuevas formas de ver, pensar y ser de los niños y niñas.

Como se ha señalado, metodológicamente se requirió ir a los discursos, a los tratados de diferentes disciplinas (la psicología, la historia, la pedagogía, la sociología y el derecho), a las políticas y a las prácticas sociales que se han desarrollado en torno a los niños y niñas; también recoge la diversidad de estas significaciones imaginarias que han asumido y determinado sus modos de vida en una época y cultura determinadas, es decir, establece esas relaciones dialécticas entre los discursos, las condiciones materiales, las políticas, las ideas y formas de representación que los niños y niñas han tenido en épocas y sociedades particulares.

Partiendo de esta premisa, se reconoce que la infancia y su desarrollo están relacionados a la sociedad y a la cultura, por lo tanto es necesario transitar por fronteras y marcos epistémicos diversos y lecturas interpretativas que develan las formas de constitución de los sujetos, de los saberes y las prácticas, lo cual tiene como fuente los estudios y tratados que han develado imágenes, representaciones y concepciones de infancia a través del constructo socio-histórico, para mostrar la existencia de significaciones sociales imaginarias compartidas y desentrañar aquellas que generan discontinuidad, instituyendo cambios en las formas de pensamiento, sentimientos, relaciones y condiciones de vida con los niños y niñas en diferentes épocas.

Es así como los imaginarios, en cuanto construcciones sociales, están anclados al desarrollo histórico-social de las sociedades y por tal razón se configu- 
ran, irrumpen, se transforman y aparecen instaurados en tiempos y sociedades particulares, en una historia que se teje desde la constitución de tres matrices históricas.

Una matriz histórica es un conjunto de significaciones imaginarias sobre la infancia presente en una época determinada y en una sociedad particular. Estas matrices son: la infancia "premoderna-antigua", la infancia "moderna" y la infancia "contemporánea o postmoderna". Estas matrices se establecen desde la existencia de elementos que conforman las significaciones imaginarias, como son los sentimientos, las maneras de nombrar o referir la infancia, los conceptos y las prácticas que se realizan en una época, sin dejar de lado que también permiten mostrar la imbricación, las continuidades y discontinuidades que se presentan en la constitución de los imaginarios sociales sobre la infancia. Las matrices históricas refieren a los contextos culturales que aportaron a la configuración de nuestra identidad como colombianos, por tanto se recogerán y contrastarán esas significaciones imaginarias de occidente con algunos estudios recientes que sobre la infancia latinoamericana y colombiana se han producido ${ }^{10}$.

Metodológicamente, la investigación adoptó el enfoque de la investigación histórica interpretativa, de carácter documental, que hace referencia a los estudios que desarrollan procesos de indagación orientados a la comprensión y transformación de ideas, representaciones en torno a un objeto de investigación, en este caso las significaciones imaginarias sociales sobre infancia. De modo que esta parte de la investigación utiliza como fuente el documento, centrando la mirada en la producción discursiva de una época determinada en torno a la infancia, discursos que, considerados como los más relevantes, se encuentran registrados en libros, estudios, tratados pedagógicos, psicológicos, en los cuales fue posible rastrear y hacer emerger desde el lenguaje, ese sinnúmero de significados y sentidos que se han construido en torno a la infancia en Occidente, mostrando una amalgama de simbolizaciones y representaciones sobre la infancia, los niños y las niñas.

Desde esta perspectiva, la sistematización y el análisis de los documentos se realizó buscando en el discurso lo que se dice, se piensa y cómo se actúa sobre la infancia; situando cada uno de ellos en los contextos definidos por las matrices históricas, con lo cual fue posible establecer grupos de significaciones instituidas e instituyentes, pero, además, comprender la evolución del concepto de infancia en clave de tiempo histórico, sus significaciones, desplazamientos, rupturas y continuidades.

$10 \mathrm{Al}$ respecto, sobre historiografías recientes de la infancia desde América Latina se puede consultar: María Victoria Alzate, "El 'descubrimiento' de la infancia: Historia de un sentimiento", Revista Electrónica de Educación y Psicología, año 1, n. ${ }^{\circ} 1$ (julio de 2004); José María Borras, "Presentación del dosier: 'Historia de la Infancia”, Cuadernos de Historia Contemporánea, vol. 24 (2002): 147-149; Martha Cecilia Herrera y Yeimy Cárdenas Palermo, "Tendencias analíticas en la historiografía de la infancia en América Latina", Anuario Colombiano de Historia Social y de la Cultura, 40, n. ${ }^{\circ}$ (2013): 279-311; Susana Sosenski y Elena Jackson, coords., "Nuevas interpretaciones de la historia de la infancia en América Latina: entre prácticas y representaciones", Estudios de Historia Moderna y Contemporánea de México, n. ${ }^{\circ} 46$ (2012); Absalón Jiménez Becerra, "Pensamiento pedagógico colombiano: Martín Restrepo Mejía. Una mirada a sus conceptos de pedagogía, infancia, maestro y escuela, Revista Historia de la Educación Latinoamericana, 19, n. ${ }^{\circ}$ 29, (2017): 254-269, https://doi.org/10.19053/01227238.7578; Zaira Navarrete Cazales. "Formación de Profesores en las Escuelas Normales de México. Siglo XX”. Revista Historia de la Educación Latinoamericana 17 n. ${ }^{\circ}$ 25, (2015):17-34. https://doi. org/10.19053/01227238.3805. 
La infancia premoderna-antigua: Significaciones imaginarias en la Europa del medioevo

El primer grupo de significaciones imaginarias referidas a la infancia está inmerso en un contexto histórico social "premoderno", en el cual, como lo señala Philippe Ariès ${ }^{11}$, la escuela medieval de los clérigos y mercaderes no distinguía las edades de los alumnos, ni señalaba ninguna condición específica de la niñez. Esta escuela integraba a niños y adultos y no daba criterios de clasificación por edad o grado de dificultad. Veamos las significaciones más relevantes de esta matriz:

La infancia asociada a edades de la vida. Las significaciones imaginarias de infancia, niño y niña, de esta época en la sociedad europea (que, como se demostrará más adelante, son muy diferentes a la constitución del imaginario sobre infancia en las sociedades premodernas de América Latina) tienen como característica las asociaciones verbales de infancia a las edades de la vida, cada etapa de la vida humana se significaba con términos como "infancia, puerilidad, juventud, adolescencia, vejez y decrepitud"; cada una de estas asociaciones verbales significaba un período particular de la vida determinadas por una mirada biologicista de la vida. "La primera edad es la infancia, que fija los dientes, y esta edad va desde el nacimiento del niño hasta los siete años; en ella, al recién nacido se le llama niño (infans), que es lo mismo que decir no hablante, porque en esta edad no puede hablar bien ni formar sus palabras perfectamente[... $]^{\prime 12}$. Es así como el concepto de infancia se encuentra inmerso en el sentimiento común de la vida y la vida como un fenómeno biológico.

Jacques Gélis ${ }^{13}$ en su artículo "La individualización del niño", un estudio centrado en la imagen de cuerpo que se tenía en la Edad Media, muestra cómo este proceso de individualización se va transformando con la emergencia de algunos elementos culturales en los inicios de la modernidad.

La imagen del cuerpo era ambivalente. Cada ser tenía su cuerpo, su propio cuerpo, pero la dependencia respecto del linaje, la solidaridad de sangre, era tan fuerte que el individuo no podía sentir su cuerpo como plenamente autónomo: este cuerpo era el suyo, pero también un poco el de "los demás", el de la gran familia de los vivos y de los antepasados. "El individuo sólo disponía del suyo en la medida en que este disfrute no contrariara los intereses de la familia [...]. Su único deber era dar la vida"14.

La infancia como sentimiento ausente. Este momento se refiere a la indiferencia, a las escasas alusiones a los niños; la infancia es una etapa de vida que se pasa rápidamente y como está condicionada a los recursos materiales, la muerte de un hijo no es trascendental; se criaban los necesarios para sostener el linaje. Es solo en los albores de la alta Edad Media cuando esta condición comienza a mo-

\footnotetext{
11 Philippe Ariès, El niño y la vida familiar en el antiguo régimen (Madrid: Editorial Taurus, 1987).

12 Ibíd., 41.

13 Jacques Gélis, "La individualización del niño", en Historia de la vida privada: Del Renacimiento a la Ilustración, dir. de Philippe Ariès y George Duby, t. III (Madrid: Editorial Taurus, 1991).

14 Ibíd., 294.
} 
dificarse y se expresa en la preocupación de las ciencias médicas por la salud y las necesidades físicas de los niños y su preservación.

La poca importancia que se le otorgaba al niño se refleja en el arte medieval, que lo representaba como un adulto en miniatura, frente a lo cual considera que "[...] si el arte medieval representaba al niño como un hombre reducido, en miniatura, 'eso [...] no interesa a la existencia, sino a la naturaleza del sentimiento de la infancia'"15. Esto significa que los niños no tenían un lugar en el mundo y no se les reconocían sus necesidades y particularidades.

Los niños y las niñas objetos del adulto. Ariès identifica un sentimiento superficial del niño que denomina mimoseo, "reservado para los primeros años cuando el niño era una cosita graciosa. La gente se divertía con él como si fuera un animalillo, un monito impúdico"16. Este tipo de actitudes y asociaciones verbales muestran que la presencia del niño es tomada solo como un objeto de observación y cuidado mientras preste o cumpla una función en el mundo del adulto. Sin embargo, esta significación de la infancia es uno de los elementos que entre los siglos XV y XVI comienza a ser cuestionada por los moralistas y pedagogos de la época, quienes, con la intensión de generar valores cristianos, señalaron que este sentimiento de "mimoseo" originaba la mala crianza.

La infancia como representación de santidad. Esta significación de la "santa infancia" se imbrica y permea desde finales del siglo xv y permanecerá hasta finales del siglo xix. Así, en la Edad Media la iconografía religiosa toma como objeto de representación a los niños y niñas como significado de benevolencia, bondad y pureza, una imagen sagrada que tiene como propósito establecer una relación intrínseca con el arquetipo, posee fuerza, virtud, gracia, que se une a la idea de revelación, mensaje o profecía. Este imaginario establece una conciencia colectiva en torno a la infancia y una significación de ser niño o niña asociada a adjetivos como "niños del cielo, niños de Dios, angelitos y niños buenos".

La infancia "graciosa"; iconografía laica. De esta significación imaginaria en los siglos XV y XVI, se desprende un imaginario laico de la infancia, pero como lo afirma Ariès, no es una representación del niño solo; el niño aparece inmerso en las costumbres y en la cotidianidad de la familia y la sociedad, "[...] el niño en la familia, el niño y sus compañeros de juegos, que son frecuentemente adultos, niños entre la multitud, pero bien 'compaginados', en los brazos de su madre, o sujetos por su mano, o jugando, o a veces orinando"17.

Una de las circunstancias de vida de niños y niñas es su alta tasa de mortalidad, especialmente en el mundo social popular y campesino, que se conjuga en el siglo xv con el infanticidio y el abandono, que provoca la creación de hospicios. En las clases altas los niños son "un pequeño ser adulado y colmado -en las familias acomodadas - de cuidados y de mimos; todo el mundo le abraza, [...] le chupetea o le acuna con canciones; los cuentos de brujas y otros que no

15 J. L. Flandrin citado por Ariès en El niño..., op. cit., 15.

16 Ariès, El niño..., op. cit., 10.

17 Ibíd., 62. 
lo son le producen una impresión de delicioso terror $[. . .]^{\prime 18}$. Sin embargo, como señalan estos historiadores, cuidados y caricias se dan solo cuando los niños pueden andar y hablar, es decir, cuando ya pueden interactuar con el adulto.

La infancia moderna en la cultura de Occidente: Emergencia de nuevas significaciones imaginarias y transformación de condiciones de vida de la niñez

El segundo grupo de significaciones imaginarias corresponden a la infancia "moderna"; a partir del Renacimiento (siglos XVI y xvir) la infancia comienza a adquirir la significación psicológica y cultural que aún en la actualidad se le atribuye. La infancia aparece como un concepto moderno que intenta universalizar una síntesis de dimensiones (edad, dependencia de ciertos cuidados y formas de trato, particulares necesidades educativas, formas de aprendizaje y desarrollo de facultades, entre otras), todo lo cual aparece en relaciones comprensibles desde una mirada cultural.

En esta matriz histórica se hace evidente la hegemonía de las ideas positivistas, que asumían las lógicas del adulto como las únicas posibles; en estas lógicas la imaginación infantil y sus diferentes formas de expresión fueron consideradas como eventos insignificantes. Este período estuvo marcado por la ausencia forzada del niño del espacio reflexivo, racional, consciente, por considerarse un recurso exclusivo de los adultos ${ }^{19}$. El concepto de infancia fue operado, durante mucho tiempo, como un enunciado que hace referencia a un lapso de vida común y lineal, transitado por todos los niños sin distinciones sociales. Por ello, la infancia, como estado natural, ha sido objeto de protección, inversión, control y represión.

En síntesis, se pueden caracterizar las significaciones imaginarias de esta matriz histórica cultural señalando que: "El telos de la modernidad es el progreso continuo y normatizado como evolución. Surge la infancia como el origen de las características del adulto racional. Desde el nacimiento se uniforma la trayectoria de la vida imponiéndole una dirección/finalidad, secuencia de etapas según la dimensión cronológica" ${ }^{20}$. Veamos algunas de las significaciones que emergieron en esta matriz histórica.

Los niños y las niñas entre lo público y lo privado. Entre los siglos xV, xVI y xvII, aproximadamente, como consecuencia del paso de lo público a lo privado y la propagación de la idea moderna de la individualización y la privatización, el imaginario social sobre infancia es una prolongación de la matriz premoderna. En los albores de la modernidad europea surgen significaciones imaginarias de los niños y las niñas centradas en la conservación de la vida y el cuidado del cuerpo del niño en el ámbito familiar. Costumbres culturales que configuraron desde la Edad Media una conciencia naturalista de la vida, en la cual la conservación de la especie es función fundamental de la mujer, quien es la encargada

18 Georges Duby, "La vida privada de los notables toscanos en el umbral del Renacimiento", en Historia de la vida privada: de la Europa feudal al Renacimiento, dir. de Philippe Ariés y Georges Duby, t. II (Madrid: Taurus, 1991), 235.

19 Aline Helg, La educación en Colombia, 1918-1957: una historia social, económica y política (Bogotá: Universidad Pedagógica Nacional/Plaza \& Janés Colombia, 2001).

20 Rabello de Castro, op. cit., 16. 
de llevar el niño en el seno, alimentarlo y alumbrarlo. Esta conciencia de la vida y del niño como conservación del linaje predominará en la modernidad hasta finales del siglo xIx, en sociedades que continuaban siendo profundamente rurales.

Los niños y las niñas emergen como objeto de preservación: A finales del siglo xIV emerge en la sociedad occidental una nueva forma de relación con los niños; esta voluntad de salvar al niño se aumenta de manera especial en el transcurso del siglo xviI, lo cual constituye una nueva concepción de la vida y del tiempo. "Prolongar la vida, abreviar los sufrimientos gracias a los cuidados que prodiga ese especialista del cuerpo que es el médico, no constituyen tampoco un empeño nuevo, pero la voluntad de cuidarse y de curarse se manifiesta con tanta fuerza desde el siglo xvi que denota a todas luces que el hombre se ve a sí mismo con otros ojos" ${ }^{21}$.

En esta época, la preocupación por la vida del niño, por la conservación de la infancia, tiene como efectos la producción y publicación de literatura científica desde diferentes disciplinas, donde el niño se convierte en objeto de estudio e intervención, configurándose así un nuevo sentimiento hacia la infancia y una nueva representación sobre la niñez, a lo que algunos estudiosos denominan "el descubrimiento del niño".

El niño, un ser diferente al adulto. Los niños son pensados como parte de una sociedad; J. J. Rousseau, el gran pensador de la infancia en el siglo xvIII, en su obra Emilio (1762) estableció desde la pedagogía el descubrimiento de la infancia moderna. Ubicando el lugar de los niños como niños, difundiendo que cada etapa de la vida debe ser considera de acuerdo con su "madurez" y tendiente a la perfección, por lo tanto, se hacía necesario considerar al niño en el niño. Con ello se descubre al niño que existe como un ser sustancialmente diferente al adulto y que su evolución depende de sus propias capacidades. Desde esta premisa, la psicología y la pedagogía establecen los principios del desarrollo infantil que marcan la nueva infancia y el nuevo niño e instauran una significación en la cual el niño deja de ser nombrado y adjetivado como "animalito", "plantita" o "adulto en miniatura" y se lo reconoce como un ser humano con características y necesidades propias de su desarrollo.

Esta concepción de Rousseau, del niño diferente al adulto y la posibilidad de su educabilidad desde la naturaleza y en libertad, enmarca un espíritu de la mentalidad de la época en la cual se va debilitando la primacía de la conservación del linaje y se va acrecentando la importancia del poder individual en el desarrollo de la relación individuo-grupo, idea o principio que es fundamento del pensamiento moderno.

La infancia como etapa de vida. En el desarrollo de esta historiografía sobre las principales significaciones imaginarias de infancia, niño y niña y su configuración en el pensamiento de occidente, la idea de la "infancia como etapa de vida", como trayecto de tiempo lineal, segmentado y homogéneo aparece por el surgi-

21 Gélis, op. cit., 297. 
miento de los discursos disciplinares como la psicología, la pedagogía, la pediatría y la sociología, discursos que van consolidando la significación imaginaria de la infancia como "etapa" de esa vida; de esta significación se desprenden un sinnúmero de significaciones en la modernidad, que configura el imaginario social sobre infancia que predomina en occidente aproximadamente durante seis siglos y que deviene hasta nuestros días. Es en las disciplinas donde emerge lo que ha dado en llamarse "la causa de los niños"22. Esta causa permite evidenciar que, unido a la idea de la infancia, se va develando el niño como sujeto y se valora como parte de la especie humana y como una persona.

Se reconoce, entonces, que desde mediados del siglo xix, la psicología, como ciencia humana, hace grandes aportaciones al posicionamiento de los niños en los imaginarios sociales de occidente, con grandes contribuciones como las de Sigmund Freud ${ }^{23}$, quien en su teoría de la sexualidad se ocupa, justamente, de la sexualidad infantil, con lo cual comienza una nueva valoración de la infancia.

Desde este gran imaginario de occidente aportado por Freud, la infancia, los niños y las niñas son develados y ahora examinados no solo desde la sexualidad, sino desde sus formas de saber. Freud denuncia que a los niños no se les ha tendido en cuenta y en sus estudios allana el camino para su reconocimiento como un sujeto con necesidades particulares a lo que considera "negligencia de lo infantil".

Los niños objeto de protección de la familia. Otra característica de la modernidad y que incide para que se constituya un nuevo sentimiento sobre la infancia, como sostiene Gélis, es la ciudad. "Nadie duda de que la ciudad, lugar de innovación por excelencia, diera la pauta. ¿Acaso no fue la ciudad donde emergió progresivamente, desde el siglo $\mathrm{xv}$, la 'familia moderna' reducida a la pareja con sus hijos? $[\ldots]^{\prime 24}$. De las grandes familias extensas que se ubicaban en los amplios espacios rurales, se pasa a los espacios urbanos más pequeños, tanto por extensión como porque ellos comienzan a albergar mayor número de personas. A finales del siglo xv, la familia cambia su configuración y se reduce a la pareja con hijos "[...] En este medio reconstruido por el hombre, en esta ciudad del Renacimiento 'pensada como cuerpo' cada vez con más frecuencia, la reducción a la familia nuclear implica el acondicionamiento de un espacio doméstico más íntimo ${ }^{25}$. Allí los niños son albergados y dejan de estar bajo la responsabilidad de otros miembros de la familia y se vuelven responsabilidad de los padres. Es así como estos cambios de la familia extensa a la familia nuclear generan el cambio de las pautas de crianza, estableciendo nuevas formas de relación con los niños.

Los niños como alumnos. Este nuevo sentimiento de reconocimiento del niño como el centro de la familia, que lo debe rodear de afecto y complacencia, da origen también a un discurso moralista y educativo, un discurso que señala que la familia sola y sus excesos de consentimiento no son suficientes para cumplir

22 Françoise Dolto, Las etapas de la infancia. Nacimiento, alimentación, juego, escuela (Barcelona: Paidós, 2002).

23 Sigmund Freud, Obras completas (Buenos Aires: Amorrortu, 1982).

24 Gélis, op. cit., 299.

25 Ibíd. 
con la educación de los niños y los hombres futuros, idea que toma prevalencia durante todo el siglo xvir y hasta mediados del siglo xx.

Desde estos discursos se muestra que la sensibilidad y los sentimientos de los adultos en la modernidad están ligados a la educación y al desarrollo de estructuras educativas, en las cuales los padres depositan parte de la responsabilidad en la formación de los niños para formar los adultos del futuro. Surge así la escuela, desde mediados del siglo xviI, como una institución social encargada de transmitir culturalmente las reglas de comportamiento conformes las exigencias de la época.

Y las nuevas estructuras educativas, en particular las de los colegios, cuentan rápidamente con la adhesión de los padres. En efecto, éstos se convencen de que su hijo está siempre a merced de instintos primarios que es preciso contener y de que es importante "someter sus deseos al gobierno de la Razón". Llevar un niño a la escuela es, por tanto sustraerle a la naturaleza. [...] La nueva educación debe su éxito a que conforma los espíritus y, al mismo tiempo, responde a las exigencias de un individualismo que aumenta sin cesar. [...] Una conciencia de la vida que ya no implica el respeto de las antiguas solidaridades y que pretende valorar al individuo y obliga a volverse hacia terceros, preceptores y directores de estudios, que tienen como misión hacer que el niño acceda a conocimientos que no podría recibir de sus padres $^{26}$.

La escuela tiene la función de contener y reprimir los instintos naturales del niño, que fueron exacerbados en el proceso de emergencia del niño como individuo en la sociedad occidental por la Iglesia y su predominio, con representaciones ideales del niño "místico" y el niño "Cristo", el niño como "bien de Dios" o como "maldición divina". Representaciones que consolidan la significación imaginaria de la "infancia santa", que dominará y determinará los sentimientos de piedad, compasión y las acciones de intervención hasta mediados del siglo xx en la modernidad.

La pedagogía ha considerado a los niños y niñas como cuerpos débiles, ingenuos, manipulables y siempre en proceso de formación. A mediados del siglo $\mathrm{xx}$, los niños y niñas son obligados a emigrar del seno de la familia a las instituciones educativas para que justamente puedan superar la carencia que les es constitutiva.

Aquí se relacionan dos procesos culturales: el nacimiento de la infancia y la aparición de la escuela. En donde "la infancia se convirtió en objeto privilegiado de todos los proyectos de transformación biológica, social, económica y política de la población; se considera que éste era el período de desarrollo individual en el cual se debían sembrar y cultivar las semillas de un mejor futuro para la sociedad y la raza. En la infancia se conjugaban tanto los mayores peligros para

26 Ibíd., 303. 
la raza como las mayores esperanzas e ilusiones de progreso y bienestar colectivo" $^{\prime 27}$.

En esta matriz histórica, la infancia, al constituirse en centro de todo tipo de intervenciones, se le asigna su condición de promesa de futuro, lo que significó crear auténticas tecnologías de información - máquinas civilizatorias - utilizadas no solo para modelar, sino también para atenuar los instintos e impulsos frente al orden instituido y prepararlos de esta forma como objetivo del proyecto civilizatorio

La infancia contemporánea-postmoderna, significaciones imaginarias entre lo instituido y lo instituyente: transformando realidades y condiciones de vida de niños y niñas

El tercer grupo de significaciones imaginarias constituyen la matriz histórico-cultural de la contemporaneidad; época marcada por el paso cultural de lo moderno a lo postmoderno, que implicó cambios tanto en el estatuto de la razón, las creencias y la historia. Lyotard ${ }^{28}$ señala que la postmodernidad implica una transformación en el estatuto del saber, así como la presencia de la edad postindustrial consecuencia de la expansión de la población y el aumento de la capacidad productiva de los países de la postguerra también significa el fin de la idea teleológica del humanismo, frente a lo cual se instaura un mundo social, fragmentado, azaroso y disperso, en el que se acentúan los procesos de personalización, y donde la realidad y el mundo son producto de la acción creadora del hombre como experiencia común y colectiva.

En esta matriz histórico-cultural emergen nuevas concepciones; la infancia es una experiencia que se vive en el tiempo presente, en el cual es posible proyectar la vida infantil, pero no programar su futuro. En esta significación imaginaria de infancia, es claro que la preparación de los niños para sostener el proyecto civilizatorio ya no es sostenible como un argumento que supone priorizar su formación para la vida adulta por cuanto es evidente que la sociedad del tiempo traslapa el adultocentrismo con la juvenilización y la infantilización.

En este proceso se observa en primer lugar un escepticismo acerca de la previsión de un futuro esperanzador, en el cual los niños y los jóvenes tengan capacidad de decisión y transformación del orden institutito; la incertidumbre de un mundo que no ofrece opciones ha llevado a niños y niñas a configurar sus subjetividades a partir de experiencias fuera de las perspectivas familiares y sociales. $\mathrm{Y}$, en segundo lugar, el descubrimiento de ámbitos y dimensiones del mundo por parte de los niños, determinado por los cambios científicos y tecnológicos, la cultura global, las transformaciones Estado-sociedad civil, experiencias y conocimientos que trastocan el ideal de vida que el adulto quiere transmitir a los nuevos niños.

Con relación a las disciplinas y saberes expertos construidos en la modernidad, en la actualidad estos no dan cuenta de la complejidad de las dimensiones ontológica, social y cultural de los niños. Aunque no se trata de poner en contro-

27 Javier Sáenz Obregón, Óscar Saldarriaga y Armando Ospina, Mirar la infancia: pedagogía, moral y modernidad en Colombia, 19031946 (Medellín: Editorial Universidad de Antioquia, 1997), 26.

28 J. F. Lyotard, Lo Inhumano. Charlas sobre el tiempo (Buenos Aires: Ediciones Manantial, 1998). 
versia la importancia de conceptos como dimensiones del desarrollo, cognición, fisiología, así como sus prácticas investigativas, es importante reconocer que la demarcación de las edades de la vida como único criterio para estudiar la infancia se agotan frente a sus experiencias en el tiempo presente. En la actualidad, niños y niñas de la misma edad e incluso escolarizados y bajo el cuidado de sus familias, viven diferentes experiencias, tales como el trabajo, el mundo de la calle, la guerra, las relaciones sexuales tempranas, su participación en actividades de formación y uso del tiempo libre complementarias a la escuela, y su vinculación a experiencias de comunicación digital, entre otras. Aunque todos son niños y niñas, cada uno tiene formas particulares de transitar la infancia, de configurar su subjetividad y vivir la experiencia infantil.

De otra parte, si la infancia contemporánea sorprende de manera especial, a propósito de sus irrupciones frente al mundo adulto, es porque está removiendo las certezas acerca de los conocimientos e intervenciones que históricamente se habían producido sobre ellos. Esto significa que ese conjunto de saberes se muestra cada vez más incapaz de dar cuenta de la multiplicidad de modos de transitar la infancia y de las maneras particulares en que se explicita el devenir de los niños y las niñas. Esto hace también que se remueva el carácter de las instituciones que tradicionalmente se han ocupado de la atención a la niñez, las cuales evidencian su dificultad al intervenir sobre un cuerpo que es hoy superficie de inscripción de discursos y prácticas que obedecen a otros principios y lógicas, entre ellos, el mercado, los medios, las tecnologías de la información y la comunicación, y las estéticas de la propia vida ${ }^{29}$. Veamos algunas significaciones imaginarias de esta matriz:

Los niños como sujetos y la infancia como diversidad. Otros pedagogos como Jean Piage $^{30}$ y Lev Vigotsky ${ }^{31}$, desde mediados del siglo $\mathrm{xx}$, aportan nuevas significaciones imaginarias sobre la infancia que han permitido elaborar los discursos y las prácticas pedagógicas sobre la infancia en la época contemporánea. Establecen que el pensamiento del niño es cualitativamente diferente al del adulto y señalan el desarrollo por etapas y en cada etapa le corresponde una forma de organización del conocimiento, reconocen además la capacidad creadora de los niños y consideran a los niños como sujetos de experiencia.

Al reconocer al niño como un ser con capacidades, capaz de crear su mundo no por imitación sino que desde las actividades de la infancia se reelaboran las propias experiencias creadoramente, combinándolas entre sí y edificando con ellas nuevas realidades acordes con las aficiones y necesidades del propio niño, es la manera como los niños se integran a la cultura y al mundo, se reconoce así el niño en su condición de "sujeto", con un mundo propio, el de la "infancia" y a la infancia como una categoría que agrupa una diversidad de experiencias y

29 Gabriela Diker, ¿Qué hay de nuevo en las nuevas infancias? (Buenos Aires: Biblioteca Nacional/Universidad Nacional de General Sarmiento, 2008).

30 Jean Piaget, "El desarrollo mental del niño", en Seis estudios de psicología (Barcelona: Editorial Seix Barral, S. A., 1991).

31 L. S. Vigotsky, "El problema del desarrollo cultural del niño", en El problema del desarrollo cultural del niño y otros textos inéditos (Buenos Aires: Editorial Almagesto, 1998), 31-55. 
no como una etapa de vida lineal y transitada por todos los sujetos de la misma forma.

La infancia, una experiencia desde los niños como sujetos del lenguaje. En esta significación, la infancia es el presente. En este sentido, discursos como los del filósofo italiano Giorgio Agamben ${ }^{32}$ otorgan a la noción de infancia un estatuto unido al lenguaje, en donde la experiencia de la infancia es considerada como la infancia del hombre, por tanto, la infancia a la que se refiere no puede ser algo establecido cronológicamente, sino que es lenguaje, hace de la infancia una categoría que agrupa unas características propias de los sujetos y una experiencia particular y única. Esto en la medida en que se reconoce al hombre como un ser producido en y desde el lenguaje y enmarcado en tramas simbólicas y la infancia como infancia del hombre marca el inicio de éste en el mundo del lenguaje, es decir, en el mundo social.

“La idea de la infancia como una 'sustancia psíquica' pre-subjetiva se revela entonces como un mito similar al del sujeto pre-lingüístico. Infancia y lenguaje parecen así remitidas mutuamente, en donde la infancia es el origen del lenguaje y el lenguaje el origen de la infancia" ${ }^{33}$. Desde esta perspectiva la infancia se vuelve una experiencia singular, producto de la operación subjetiva del niño desde y en el lenguaje que cada niño atraviesa y experimenta desde sus constructos culturales.

La infancia como lo otro y el niño como sujeto y las subjetividades infantiles. Esta idea de la infancia ubica a la infancia en el campo de un enigma, como lo afirma Jorge Larrosa ${ }^{34}$, en donde los niños y las niñas se muestran como extraños, de los que no se sabe nada; sin embargo, este autor sostiene que desde los discursos de las disciplinas podemos saber que eso que llamamos infancia como concepto es:

[...] algo que nuestros saberes, nuestras prácticas y nuestras instituciones ya han capturado [...] no obstante, y al mismo tiempo, la infancia es lo otro: lo que siempre más allá de cualquier intento de captura, inquieta la seguridad de nuestros saberes, cuestiona el poder de nuestras prácticas y abre un vacío en el que se abisma el edificio bien construido de nuestras instituciones de acogida. Pensar la infancia como algo otro es, [...] Es insistir una vez más (en que son) los niños, esos seres extraños de los que nada se sabe, esos seres salvajes que no entienden nuestra lengua [...] Todos trabajan por reducir lo que aún hay de desconocido en los niños para someter lo que en ellos aún hay de salvaje [... $]^{35}$.

Esta significación imaginaria de la infancia contemporánea está marcada por el reconocimiento de la subjetividad de los niños, su diversidad de experiencias que, al pensarlos en el contexto de la otredad, configuran una heterogeneidad

\footnotetext{
32 Giorgio Agamben, Infancia e historia. Destrucción de la experiencia y origen de la historia (Argentina: Adriana Hidalgo Editora, 2010).

33 Ibíd., 64.

34 Jorge Larrosa, "El enigma de la infancia", en Imágenes del otro, comp. por Jorge Larrosa y Nuria Pérez de Lara (Barcelona: Virus, 1997).

35 Ibíd., 20.
} 
absoluta de experiencias diferentes a las del adulto y donde, por su diversidad, escapa a las medidas de nuestro saber y nuestro poder. Desde aquí, los niños y las niñas son reconocidos como "el otro", un sujeto de experiencia, la cual no debe ser integrada al mundo del adulto, sino que se debe asumir como lo nuevo, como lo que se encuentra.

Un autor que en la actualidad indaga por la transformación y consolidación de nuevos imaginarios, por el reconocimiento de la subjetividad infantil que determina las diversas formas de habitar y ser niños en el mundo contemporáneo; quien además ha desarrollado un compromiso político con la infancia, a partir de la creación del "laboratorio de la infancia y la ciudad" en Italia y en otras ciudades del mundo, es Francesco Tonucci ${ }^{36}$, plantea la necesidad de devolver la ciudad a los niños, de pensarla con ellos como habitantes. La ciudad debe ser el escenario desde el cual niños y niñas construyen su subjetividad y se proyectan como ciudadanos participativos, críticos y propositivos. El autor expone a lo largo de su trabajo cómo la ciudad moderna no incluye a la población infantil y mucho menos a la población vulnerable, propone estrategias para que la ciudad moderna sea incluyente y cómo, desde la escuela, la ciudad se constituya en un verdadero referente de aprendizaje, una forma de acercar la ciudad a la infancia y así garantizar los derechos que tienen los niños y niñas al conocimiento, aprendizaje y disfrute de su ciudad.

Esta significación imaginaria de los niños como el otro nos aproxima a conceptualizar la infancia, a descubrir y reconocer en la cultura la presencia del niño como "otro". Ese niño otro, es el niño, no por el recuerdo, sino por el olvido del recuerdo, por eso los niños son recuerdo y olvido, inocencia. La inocencia no significa que los niños sean inocentes, sino que están en un sitio que se llama olvido. Lo que se vislumbra en el olvido es el niño que somos o dejamos de ser y que sigue siendo. Con estas tesis, Humberto Quiceno ${ }^{37}$ refiere que todo lo que se ha construido sobre infancia y sobre los niños son conceptos y construcciones desde las significaciones de los niños en la vida de los adultos y que eso que llamamos infancia es diferente a la experiencia del niño, por lo tanto la constitución del niño como sujeto al cual se reconoce como sujeto de experiencia, de saber, de subjetividad y diversidad, plantea entonces la necesidad de construir nuevas representaciones y nuevos conocimientos que nos permitan comprender los niños actuales que permita hacer de ellos sujetos libres o sujetos institucionalizados.

Esta significación que lleva al reconocimiento del niño "otro" diferente al que fuimos o el que somos, plantea la necesidad en el mundo contemporáneo de nuevas prácticas sociales como la educación, se requiere de otra escuela y otras pedagogías que como ciencia que porta un concepto de infancia, niño y niña sea capaz de reconocer el problema del otro como diferente y en un proceso de alteridad sea reconocida la experiencia infantil como lo que establece el límite con el mundo del adulto, con la sociedad y la cultura heredada. Con ello se reconoce

36 F. Tonucci, La ciudad de los niños (Barcelona: Graó, 1996).

37 Humberto Quiceno, “Sujeto del saber en el grupo de historia de las prácticas” (documento inédito, 2010). 
también la diversidad de los niños, como sujetos diferentes al adulto, lo cual nos llevaría a plantear una sociedad incluyente que reconozca lo "otro" como lo distinto a nosotros.

La experiencia de la infancia diversa. Esta significación imaginaria de la infancia se constituye desde la idea de reconocer la diversidad de la experiencia infantil, pero también la diversidad de los niños y las niñas en los contextos culturales, sociales y económicos de cada país o región. Ello se plantea desde los estudios de la piscología, con los trabajos de Françoise Dolto ${ }^{38}$, quien reconoce la diversidad de la subjetividad infantil y se opone al encierro de la infancia en los parámetros normatizantes de la sociedad moderna, sustentados en la familia y la escuela. Sostiene que la experiencia de los niños se construye fuera de la familia y que las edades y etapas de la vida como criterio fundamental para estudiar la infancia se agotan frente a la diversidad de experiencias y formas de ser de los niños y niñas hoy.

Dolto afirma que las imágenes que tienen los padres y los adultos de los niños está basada en la idealización y proyección, lo cual hace que no se admitan errores en el comportamiento de los niños. Este imaginario de idealización hace que los padres y los niños asuman los errores como sentimientos de culpa y con gran exigencia por parte de los padres. Estas ideas frente a los problemas de los niños muestran cómo el imaginario que se tenga de ellos no solo influye en las formas de relación con el adulto, sino también en las imágenes e identidades que ellos mismos (niños) construyen y cómo afrontan las situaciones particulares de la infancia.

La infancia como categoría sociopolítica; niños y niñas como sujetos de derecho. Las significaciones imaginarias que se desarrollan desde comienzos y mediados del siglo $\mathrm{xx}$ en los discursos de las disciplinas, establecen actitudes favorables hacia la infancia, creando espacios cerrados para su culturización y socialización con el fin de brindarles la protección a su condición de minoría de edad en el desarrollo histórico social, otorga a la pedagogía el papel fundamental de la constitución de la infancia como sujeto social diferenciado y autónomo, que emerge desde mediados del siglo xx, pero realmente se consolida en esta primera década del siglo xxI, por lo tanto corresponde más a la matriz histórica de significaciones imaginarias de la contemporaneidad. Sin embargo, desde finales del siglo xx aparece la idea del niño como sujeto de derecho, que ubica a la infancia como una categoría sociopolítica.

La significación imaginaria del niño como sujeto de derecho deviene de la infancia como un concepto y una realidad que determina el periodo de vida y la experiencia de una población que va desde el nacimiento de la cría humana hasta los 12 o 18 años. Por lo tanto, se entiende la infancia como el conjunto de características psicobiológicas de unos sujetos en estado de desarrollo, hasta que no alcancen las características de un estado posterior, de modo que la población

38 F. Dolto, op. cit. 
con estas características debe ser protegida, cuidada y asistida para que complete su desarrollo.

Algunos autores como Ferran Casas señalan que fue necesaria una convención separada de las relativas a todos los seres humanos para reconocer que los niños tenían algún tipo de derecho. Así, el reconocimiento de los niños como sujetos de derecho pasa también por una génesis histórica donde estos derechos no son producto "de una reflexión sobre la infancia, sino al reconocimiento de la existencia de un problema social a solucionar: la falta de alguien que cuidara a los niños y las niñas abandonados [...]"39.

Esto ha implicado que desde el momento en que los niños adquieren el estatus social y cultural de sujetos de derecho, hay un cambio profundo en las maneras de entender a la infancia y una revalorización de la experiencia y la vida infantil, puesto que no solo tienen derecho a ser protegidos, atendidos y cuidados; sino que tienen derechos civiles y políticos que están vinculados a las libertades básicas de la formación personal, como son el "libre desarrollo de su personalidad" y se les garantizan las libertades políticas, como la participación de la infancia en las decisiones sociales como un grupo poblacional con reconocimiento social. Con ello se va transformando el imaginario del niño como objeto de derecho a un sujeto con amplia gama de derechos y libertades.

La infancia y el sujeto infantil como alteridad recurrente desde los medios masivos de comunicación. Si el telos de la modernidad estaba basado en un progreso continuo y normatizado como evolución que daba seguridad y apropiación, el telos de la posmodernidad, como expresión cultural de la contemporaneidad, ubica al sujeto como desarraigado, desapropiado, en donde los lugares de identificación que generaban arraigo y sentido subjetivo para la infancia como el barrio, la plaza, la casa, han sido reemplazados por el habitar en la internet, en el ciberespacio, que, como lo sostiene Lyotard ${ }^{40}$, es un transitar de los padres y de los niños en una soledad nómade y donde el contacto está determinado por los celulares en donde no hay una comunicación real y la penetración del aparato tecno-científico en el campo de la cultura no significa de ninguna manera que haya un aumento de conocimiento, de tolerancia y libertad para la infancia, en donde el tiempo se convierte en una experiencia subjetiva, que determina unos intercambios azarosos, contingentes e instantáneos que caracterizan esta época posmoderna y que de una $\mathrm{u}$ otra manera ha configurado un campo de posibilidades diferentes de la subjetivación infantil.

Es así como muchos autores plantean la infancia como "mercancía", que remite al "niño como consumidor" que transita en un acontecer sin experiencia y donde la construcción de la subjetividad como experiencia y proyecto está marcada por la incertidumbre del intercambio en la red social. La instantaneidad tecnológica, asumida como un movimiento rápido y breve, significa una satisfacción inmediata de las necesidades, pero también el agotamiento y la des-

39 Ferran Casas, Infancia: perspectivas psicosociales (Barcelona: Paidós, 1998), 146.

40 Lyotard, op. cit. 
aparición inmediata del interés, significaciones que marcan en la actualidad las experiencias de los sujetos, la construcción de las intersubjetividades y la construcción de la experiencia infantil, en donde el intercambio con otros en esa realidad virtual es instantánea y efímera, perdiendo la construcción significativa de recuerdos y de subjetividad y la experiencia infantil se realiza solamente desde la información que sustituye la experiencia vivida.

El niño como consumidor y el fin de la infancia. Desde esta idea de la infancia reconfigurada por la influencia de los medios masivos de comunicación y los avances tecnológicos, aparte de las resistencias frente al hecho que ser sujeto niño en la contemporaneidad desde el discurso mediático implica más ser un sujeto de opinión, se debe reconocer y replantear la experiencia del sujeto niño como conocimiento y práctica que configura diferentes sujetos y subjetividades infantiles. "El niño, además de recibir los efectos de su medio, es a su vez generador de intercambios y puede tener injerencia casual en los sucesos y sus marcas, al pertenecer a una red de interacciones y combinaciones infinitas dentro de un magma de saberes e incertidumbres $[\ldots]^{\prime \prime 4}$.

Esta idea de la experiencia del niño en la red ha planteado que la infancia se reduce en tiempo de vida y que los niños, según Buckingham, se hacen mayores sin haber tenido infancia, lo que ha originado nuevas formas de trato para los niños y las niñas, pero a su vez nuevas formas como ellos se comportan; “los críticos señalan las pruebas de la existencia de [...] la progresiva desintegración de la vida familiar, y sostienen que se han perdido para siempre la seguridad e inocencia que caracterizaba la experiencia infantil de las generaciones anteriores" ${ }^{\prime \prime 2}$.

\section{CONCLUSIÓN}

Esta historiografía de la infancia ha permitido construir un concepto de la infancia como una categoría histórico social, un concepto ligado a una cultura y a los modos de ser de una sociedad, que nos obliga a transitar por fronteras epistémicas diversas que den cuenta de los procesos de constitución de los niños, niñas y jóvenes, de sus saberes y de sus experiencias.

En este paso por la construcción y develación de las significaciones imaginarias de infancia en el mundo de Occidente, se puede percibir cómo los imaginarios sociales sobre la infancia se imbrican, algunos continúan traslapados en el cambio de las costumbres, la cultura y permanecen en la institución social y cómo ellos son el cimiento de la construcción de aquellos imaginarios instituyentes que han llevado a la transformación de las formas de pensar, decir y establecer las prácticas en una sociedad.

Así mismo, esta historiografía que se construye desde las continuidades, desplazamientos y rupturas de las significaciones imaginarias, aporta a la confi-

\footnotetext{
41 Betty Korsunsky, en Niños del psicoanálisis, comp. por Ada Rosmaryn (Buenos Aires: Asociación Escuela Argentina de Psicoterapia para Graduados), p. 10.

42 David Buckingham, Crecer en la era de los medios electrónicos: Tras la muerte de la infancia (España: Ediciones Morata, 2002$), 32$.
} 
guración de la diversidad y pluralidad de las formas de ser niño o niña en la contemporaneidad.

Se devela también la presencia de los dualismos entre un imaginario instituido y unos imaginarios que se presentan como instituyentes en la sociedad y que han orientado las relaciones, las prácticas de crianza, cuidado y educación de la infancia.

Esta historiografía de la infancia, si bien presenta la emergencia de significaciones instituidas en la contemporaneidad, también muestra la existencia y permanencia de un imaginario institucionalizado en los diferentes ámbitos de la sociedad y la cultura, los cuales actúan aún como constructores de realidades y dan cuenta de la existencia de los niños y niñas.

Es clara, además, la lenta modificación de los imaginarios sociales sobre la infancia, la incidencia de la cultura en ellos, en los saberes y prácticas sociales que modifican las formas de relación y el trato con la infancia.

La infancia, como categoría social en la modernidad, se construyó a través de los medios impresos que permitieron acumular una gran cantidad de saberes que, como secretos, eran mediados por los adultos, manteniendo el control de los "secretos de la vida", experiencia que marcaba una diferenciación entre la vida adulta y la infantil, con la irrupción de los medios masivos y las nuevas tecnologías, todos, la literatura, los textos, los saberes y los secretos de la vida están a disposición de los niños, por ende esa diferenciación, esos límites, se han desdibujado y se han ido perdiendo, no solo los secretos de la infancia, sino también la infancia como categoría social. La incidencia de un mundo marcado por las "tics" y el internet, ha logrado configurar otros sujetos niños (infancias) y otros modos de ser niño o niña en el marco de una sociedad globalizada.

\section{FUENTES}

Ariès, Philippe. El niño y la vida familiar en el antiguo régimen. Madrid: Editorial Taurus, 1987.

Castoriadis, Cornelius. La institución imaginaria de la sociedad. Francia: Editorial Senil, 1975. Dolto, Françoise. Las etapas de la infancia: nacimiento, alimentación juego, escuela Barcelona: Paidós, 2002.

Duby, Georges. "La vida privada de los notables toscanos en el umbral del Renacimiento". En Historia de la vida privada: De la Europa feudal al Renacimiento, dirección de Philippe Ariès y Georges Duby, tomo II. Madrid: Taurus, 1991.

Febvre, Lucien. Combates por la historia. Barcelona: Editorial Ariel, 1982.

Freud, Sigmund. Obras completas. Buenos Aires: Amorrortu, 1982.

Foucault, Michel. Vigilar y castigar: nacimiento de la prisión. México: Siglo xxI, 1976.

Gélis, Jacques. "La individualización del niño". En Historia de la vida privada: Del Renacimiento a la Ilustración, dirección de Philippe Ariès y Georges Duby, tomo III. Madrid: Editorial Taurus, 1991.

Helg, Aline. La educación en Colombia, 1918-1957: una historia social, económica y política. Bogotá: Universidad Pedagógica Nacional/Plaza \& Janés Colombia, 2001.

Rabello de Castro, Lucía, Infancia y adolescencia en la cultura del consumo. Argentina: Lumen, 2001.

Piaget, Jean. "El desarrollo mental del niño". En Seis estudios de psicología. Barcelona: Editorial Seix Barral, S. A., 1991 


\section{REFERENCIAS}

Agamben, Georgio. Infancia e historia. Destrucción de la experiencia y origen de la historia. Buenos Aires, Argentina: Adriana Hidalgo Editora, 2010.

Alzate, María Victoria. "El descubrimiento de la infancia: historia de un sentimiento". Revista Electrónica de Educación y Psicología, año 1, n. ${ }^{\circ} 1$ (2004).

Anzaldúa Arce, Raúl E. "Lo imaginario como significación y sentido". En Imaginario social: creación de sentido, coordinado por Raúl Anzaldúa. México: Universidad Pedagógica Nacional, 2010.

Berger, Peter y Thomas Luckmann. La construcción social de la realidad. Argentina: Amorrortu editores, 2003.

Borras, José María. "Presentación del dosier: 'Historia de la Infancia'”. Cuadernos de Historia Contemporánea, vol. 24 (2002): 147-149.

Buckingham, David. Crecer en la era de los medios electrónicos: Tras la muerte de la infancia. España: Ediciones Morata, 2002.

Casas, Ferran. Infancia: perspectivas psicosociales. Barcelona: Paidós, 1998.

Diker, Gabriela. ¿Qué hay de nuevo en las nuevas infancias? Buenos Aires: Biblioteca Nacional/ Universidad Nacional de General Sarmiento, 2008.

Herrera, Martha Cecilia y Yeimy Cárdenas P. “Tendencias analíticas en la historiografía de la infancia en América Latina". Anuario Colombiano de Historia Social y de Cultura, 40, n. 2 (2013): 279-311.

Jiménez, Absalón. “Pensamiento pedagógico colombiano: Martín Restrepo Mejía. Una mirada a sus conceptos de pedagogía, infancia, maestro y escuela". Revista Historia de la Educación Latinoamericana, 19, n. 29 (2017): 254-269.

Korsunsky, Betty. En Los niños del psicoanálisis, compilado por Ada Rosmaryn. Buenos Aires: Asociación Escuela Argentina de Psicoterapia para Graduados, 2005.

Navarrete Cazales, Zaira "Formación de Profesores en las Escuelas Normales de México. Siglo XX". Revista Historia de la Educación Latinoamericana 17 n. ${ }^{\circ}$ 25, (2015):17-34. https://doi. org/10.19053/01227238.3805.

Larrosa, Jorge. "El enigma de la infancia”. En Imágenes del otro, compilado por Jorge Larrosa y Nuria Pérez de Lara. Barcelona: Virus, 1997.

Lyotard, Jean-François. Lo inhumano. Charlas sobre el tiempo. Argentina: Manantial, 1998.

Quiceno, Humberto. "Sujeto del saber en el grupo de historia de las prácticas". Documento inédito, 2010.

Sáenz Obregón, Javier, Óscar Saldarriaga y Armando Ospina. Mirar la Infancia: pedagogía, moral y modernidad en Colombia, 1903-1946. Medellín: Editorial Universidad de Antioquia, 1997.

Sosenski, Susana y Elena Jackson (coords.). “Nuevas interpretaciones de la historia de la infancia en América Latina: entre prácticas y representaciones". Estudios de Historia Moderna y Contemporánea de México, n. ${ }^{\circ} 46$ (2012).

Tonucci, Francesco. La ciudad de los niños. Barcelona: Graó, 1996.

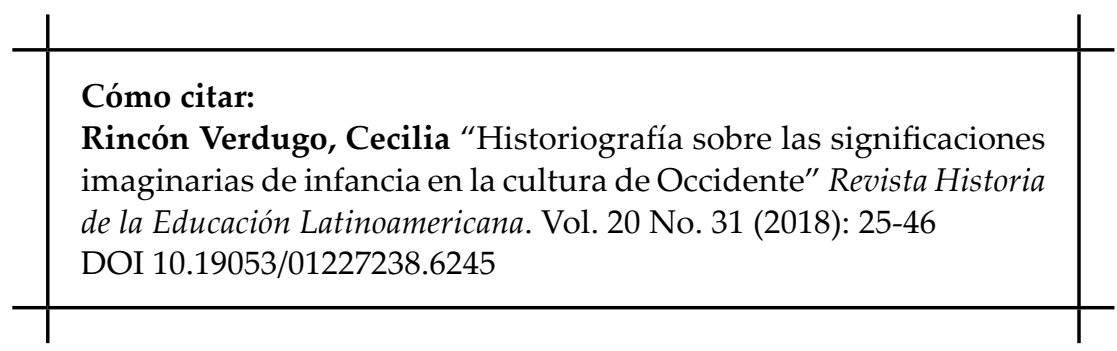

